\title{
Comparison of the Flexi laryngeal mask airway vs. endotracheal intubation for paediatric ophthalmic surgery
}

\author{
Qazi Ehsan Ali ${ }^{1}$, Syed Hussain Amir ${ }^{2}$, Uzma Firdaus ${ }^{3}$, Abdulla Z Azhar \\ ${ }^{I}$ (MD, Associate Professor, Dept of Anaesthesiology, Jawaharlal Nehru, Medical College, A.M.U., \\ Aligarh.,U.P., India. ) \\ ${ }_{2}^{2}(M D$, Assistant Professor, Dept of Anaesthesiology, Jawaharlal Nehru, Medical College, A.M.U., \\ Aligarh.,U.P., India. ) \\ ${ }_{3}^{3}$ (MD, Assistant Professor, Dept of Paediatrics, Jawaharlal Nehru, Medical College, A.M.U., Aligarh.,U.P., \\ India. ) \\ ${ }^{4}$ (MBBS, Resident, Dept of Anaesthesiology, Jawaharlal Nehru, Medical College, A.M.U., Aligarh.,U.P., India.)
}

\begin{abstract}
Background: The study aims at assessing the advantages of Flexi laryngeal mask airway (Flexi LMA) over endotracheal intubation in minimizing the pressor response as well as the rise in intraocular pressure in paediatric patients undergoing ophthalmic operations.

Method: Sixty paediatric patients aged 4-12 years of ASA grade I and II meant for ophthalmic surgeries were divided into two groups of 30 patients each by a computer generated table. Group I patients underwent Flexi Laryngeal mask airway insertion and group II patients received endotracheal intubation. All the patients received similar premedication and anaesthetic drugs on per $\mathrm{kg}$ body weight basis. Patients were induced with Propofol and were maintained on Oxygen, nitrous oxide, Sevoflurane and rocuronium bromide. Changes in heart rate, mean arterial pressure and intraocular pressure were noted at different intervals which were markedly different in the two groups. Values so obtained were analysed using student's $t$ test and $Z$ test respectively. A p value $<0.05$ was considered to be statistically significant.

Results: Similar but marked attenuated pattern of response was seen in group I patients compared to group II patients. Statistically significant difference between the two groups were seen in mean arterial blood pressure, heart rate and intra-ocular pressure $(p<0.05)$.

Conclusion: Thus the use of Flexi LMA may offer some noticeable advantages over endotracheal intubation, especially for glaucoma patients as well as for those with some other associated congenital anomaly like congenital heart disease, cerebral aneurysm or even for valvular diseases.
\end{abstract}

Key words: Flexi Laryngeal Mask Airway, intubation, pressor, ophthalmic, Intraocular.

\section{Introduction}

Laryngoscopy and intubation has long been associated with significant cardiovascular responses in the form of tachycardia and hypertension ${ }^{1}$ and an increase in intraocular pressure ${ }^{2}$. Among various techniques to attenuate this response, was a new concept of use of Laryngeal Mask Airway (LMA) for airway access. The laryngeal mask airway was introduced by A.I.J. Brain in 1983. Although it does not offer airway protection against foreign material in the pharynx but provides adequate airway control to allow intermittent positive pressure ventilation ${ }^{3}$. Tracheal intubation is associated with pressor response, breath holding, coughing and also leads to an increase in intraocular pressure. Use of LMA causes less coughing, straining and breath holding ${ }^{4}$. The use of LMA is recommended as a means of avoiding the haemodynamic responses especially to tracheal intubation in circumstances where such a response might be undesirable ${ }^{5}$.

The aim of this study was to assess the use of Flexi Laryngeal Mask Airway (Flexi LMA) as an alternative to avoid or to attenuate various noxious responses of endotracheal intubation including haemodynamic derangement and to intraocular pressure changes in paediatric patients who underwent ophthalmic surgeries.

\section{Method}

After obtaining approval from the ethical committee, sixty paediatric patients of ASA grade I and II scheduled to undergo ophthalmic surgeries under general anaesthesia, were studied after obtaining informed written consent from patient's parent. Patients in this study included those who had to undergo strabismus surgery, trabeculectomy, cataract surgery and Intraocolar lens implantation (I.O.L.). The patients were divided into two groups of 30 patients each by a computer generated table. Group I consisted of patients who were subjected to Flexi LMA insertion and Group II had undergone conventional laryngoscopy and endotracheal intubation (ETT).

Patients with associated cardiovascular problems, upper respiratory tract infection, raised intraocular 
pressure and predicted difficult intubation were not included in the study. Premedication was done with inj. Fentanyl $2 \mu \mathrm{g} . \mathrm{kg}^{-1}$, inj. Midazolam $0.05 \mathrm{mg} . \mathrm{kg}^{-1}$ and inj. Ondansetron $0.1 \mathrm{mg} . \mathrm{kg}{ }^{-1}$. Patients were preoxygenated with $100 \% \mathrm{O}_{2}$. Thereafter, anaesthesia was induced using inj. Propofol $2 \mathrm{mg} \cdot \mathrm{kg}^{-1}$ and neuromuscular paralysis was achieved by inj.Rocuronium $0.1 \mathrm{mg} \cdot \mathrm{kg}^{-1}$. Standard Monitoring was done in all the cases. Intraocular pressure was measured in the non-operative eye by the ophthalmic surgeon using Schwartz tonometer after instillation of $4 \%$ topical lignocaine. Baseline parameters including heart rate, mean arterial blood pressure and intraocular pressure were noted before insertion/ intubation $\left(\mathrm{T}_{0}\right)$. Readings were then recorded 1, 2 and 3 min after insertion of Flexi LMA or tracheal intubation.

Patients were maintained on Nitrous oxide, Oxygen, sevoflurane, Rocuronium with intermittent positive pressure ventilation. At the end of surgery, residual neuromuscular blockade was reversed with inj. Neostigmine and inj. Atropine. An eye bandage was done and removal of Flexi LMA or extubation was done only after satisfactory establishment of spontaneous breathing and response to verbal command. Episodes of coughing, straining or breath holding were recorded at the end of anaesthesia.

\section{Result}

Both the group had similar demographic data (Table1). The duration of surgery was also comparable in the two groups. The increase in heart rate (Table 2), (Graph 1) and mean arterial pressure (Graph 2) after intubation and Flexi LMA insertion had the similar pattern. There was a rise of these parameters compared to the baseline values within the group. This rise was maximum at 1 minute $\left(\mathrm{T}_{0+1}\right)$ after insertion/ intubation and remained high at $2^{\text {nd }}$ minute $\left(\mathrm{T}_{0+2}\right)$ after insertion/ intubation then came down to near baseline at the end of $3^{\text {rd }}$ minute $\left(\mathrm{T}_{0+3}\right)$ (Table 2). The IOP remained almost static in Group I till $3 \mathrm{~min}\left(\mathrm{~T}_{0+3}\right)$ but IOP rose from baseline values to maximum at 1 minute post intubation $\left(\mathrm{T}_{0+1}\right)$ which was statistically significant $(\mathrm{p}<0.05)$ and gradually came down to near baseline after $3 \min [($ (Table 2)(Graph 3)].

The increase in heart rate in ETT group was statistically significant compared to Flexi LMA group 1 min after insertion/ intubation.[(Table 2)(Graph 1)] and the rise in MAP (Table 2)(Graph 2)] and IOP [ (Table 2)(Graph 3)] in ETT group was statistically significant as compared to Flexi LMA group at both I and 2 min after insertion/intubation.

Statistically significant number of patients experienced coughing and breath holding in group II patients compared to Group I patients ( $\mathrm{p}<0.05$ ). Two patients in Group II showed straining compared to 1 in Group I patients (which is statistically insignificant) at the time of extubation/removal of Flexi LMA ( Table I).

\section{Discussion}

The pressor response to laryngoscopy and intubation has been a cause of concern for anaesthesiologist especially in high risk patients. Similarly, controlling intraocular pressure in paediatric patients with acute glaucoma (congenital/ acquired) and penetrating eye injuries needs attention of the anaesthesiologist.

A reflex sympathoadrenal discharge is provoked by laryngotracheal stimulation, due to laryngoscopy and intubation ${ }^{6}$. Different parameters in this study had different trend in both the groups. The rise in haemodynamic variables including pulse rate (Graph 1) and mean arterial pressure (Graph 2) was maximum in the first minute after insertion of Flexi LMA or intubation respectively which started declining two minutes after insertion of Flexi LMA or intubation and reached near normal value after three minutes of the insertion/ intubation procedure. The rise in the haemodynamic variables were statistically significant $(\mathrm{p}<0.05)$ compared to their respective baseline values especially by the end of two minutes after the procedure and it declined to near its baseline values at the end of third minute after the completion of the procedure. Regarding the changes in the intraocular pressure (IOP) during different time interval, it has similar pattern as observed for haemodynamic parameters and the rise just after intubation was statistically significant $(\mathrm{p}<0.05)$ which declined to almost its baseline value subsequently(Graph 3). In Group I there was no significant rise in IOP. The rise in pulse rate and MAP in normal patients had no serious consequences but this transitory rise is of serious concern in patients with cerebrovascular problems, any congenital/ acquired heart disease or with raised intraocular pressure. The life threatening complications that occur due to this response include ventricular tachycardia, acute left ventricular failure, myocardial ischemia and cerebrovascular accidents. Any rise in intraocular pressure especially in patients of acute glaucoma or in perforating injuries of eye may lead to disc ischemia due to change in critical disc perfusion and also this may augment protrusion of eye content in a perforated eye resulting into permanent loss of vision.

Although the use of cuffed oropharyngeal airway (COPA) in situations of impossible mask ventilation has been claimed to be very useful alternative but can't replace the utility of LMA in difficult situations ${ }^{7}$. This sympathoadrenal discharge in response to ETT or Flexi LMA is not of much significance in normotensive patients and in patients with normal IOP, but can lead even to sudden death in high risk patients including patients of hypertension, coronary artery disease and with cerebrovascular insufficiency ${ }^{8}$. Because of this simple reason, various techniques have been deviced to obtund such responses. To attenuate such responses especially 
in high risk patients various pharmacological methods have been tried including sublingual nifedipine, lidocaine, narcotic agents, sodium nitroprusside and beta adrenergic blockers ${ }^{9-13}$. Similarly some technical modifications in securing the airway have also been successfully tried including use of laryngeal mask in place of endotracheal tube ${ }^{14-15}$. Moreover the use of LMA instead of endotracheal tube whenever feasible lowers the chances of postoperative laryngospasm during emergence and also has less incidence of coughing than endotracheal intubation ${ }^{16}$, thus saving the patients especially in paediatric age group operated for ophthalmic procedure from incisional dehiscene and rise in intraocular pressure in high risk patients ${ }^{17-18}$.

Although this cardiovascular response to laryngoscopy and intubation is a result of sympathoadrcnal discharge due to mechanical stimulation by laryngoscopy and subsequent stimulation of the larynx by intubation. The significant rise in the parameters including Pulse Rate, MAP and IOP may be linked to plasma catacholamine concentration changes due to laryngotracheal stimulation ${ }^{19}$. There is a rise in plasma adrenaline level by $51 \%$ by laryngoscopy and intubation ${ }^{20}$. The reason for greater increase in observed parameters of group II may be because of additional stimulation of laryngotracheal system by intubation which leads to further increase in the catecholamine release in circulation. For both extraocular and intraocular surgeries the Flexi LMA has advantages over endotracheal intubation in term of better intraocular pressure control, cardiovascular stability and an improved airway recovery profile with less coughing and bucking during emergence ${ }^{21}$.

The reason for increase in intraocular pressure especially in ETT group has not been clearly understood. But this may be linked with increased sympathetic activity during laryngoscopy and intubation (Group II) causing vasoconstriction and an increase in central venous pressure. Comparatively decreased sympathetic responses with the use of Flexi LMA may be due to diminished catecholamine release compared to laryngoscopy and intubation ${ }^{19}$. This may be strengthened by the fact that Flexi LMA is relatively simple and atraumatic to insert and does not require laryngoscopy before insertion which seems to be an important reason for less coughing, straining and breath holding in Group I patients compared to Group II patients (Table I).

\section{Conclusion}

Use of Flexi LMA in children for ophthalmic operations causes less rise in pulse rate, Mean arterial pressure and intraocular pressure. Flexi LMA can be used with great safety for patients undergoing ophthalmic surgeries especially if they have any associated risk factors including CVS anomalies, glaucoma or any other arteriovenous malformation including cerebral aneurysm where controlling rise in pulse rate, mean arterial pressure and intraocular pressure is of utmost importance.

\section{References}

[1] Forbes AM, Dally FG. Acute hypertension during induction of anaesthesia and endotracheal intubation in man.Br J Anaesth 1970; 42: $618-624$

[2] Watcha MF, White PF, Tyschen I and Stevens JL. Comparative effects of laryngeal mask airway and endotracheal tube insertion on intraocular pressure in children. Anaesth Analg1992; 75: 355-360.

[3] Brain A. L J. The laryngeal mask new concept in airway management. British Journal of Anaesthesia 1983; 55: 801-805.

[4] Brodrick P.M., Webster N.R. and Nunn J.F. The laryngeal mask airway: a study of 100 patients during spontaneous ventilation. Anaesthesia1989; 44: 238-241.

[5] Wood M.L.B. and Forrest E.T.S. The haemodynamic response to the insertion of the laryngeal mask airway: a comparison of laryngoscopy and tracheal intubation. Acta. Anaesth. Scand 1994; 38: 570-573.

[6] Devault M., Greifenstein F.E. and Harris L.G. Circulatory responses to endotracheal intubation in light General anaesthesia. Anaesthesiology 1960; 21:360-62.

[7] Asai T., Koga K. and Stacey M. Use of cuffed oropharyngeal airway after difficult ventilation through a facemask. Anaesthesia 1997; 52: 1236-1237.

[8] Madi M.A., Koszler H. and Yacoub. O. A method for prevention of cardiovascular reactions to laryngoscopy and intubation. Canad. Anaesth. Soc. J. 1975; 22: 316-29.

[9] Puri GD, Batra YK. Effects of nifedipine on cardiovascular responses to laryngoscopy and intubation. Br J Anaesth 1988 ; 60 : 57981.

[10] Abou-Madi MN, Keszler H, Yacoub JM. Cardiovascular reactions to laryngoscopy and tracheal intubation following small and large intravenous doses of lidocaine. Can Anaesth Soc. J 1977; 24: 9-12.

[11] Dahlgren N, Messeter K. Treatment of the stress response to laryngoscopy and intubation with fentanyl. Anaesthesia 1981 ; 36 : 1022-6.

[12] Stoelting RK. Attenuation of blood pressure response laryngoscopy and tracheal intubation with sodium nitroprusside. Anaesth Analg 1979; 58: 111.

[13] Prys-Roberts C, Foex P, Biro G. Studies of anaesthesia in relation to hypertension versus adrenergic beta receptor blockade. Br J Anaesth 1973; 45: 671-81.

[14] Braude N, Clements EAF, Hodges UM and Andrews BP. The pressor response and laryngeal mask airway insertion. Anaesthesia 1989; 44: 551-554.

[15] Wilson IG, Fell D, Robinson SL and Smith G. Cardiovascular responses to insertion of laryngeal mask airway. Anaesthesia 1992; 47: 300-302.

[16] Yu SH, Beirne OR. Comparison of LMA and ETT Complications J Oral Maxillofac Surg 2010; 68: 2359-2376.

[17] Akhtar TM, McMurray P. A comparison of laryngeal mask airway with tracheal tube for intra-ocular ophthalmic surgery. J Anesth1992; 47: 668-71.

[18] Atkinson RS, Rushman GB, Lee JA: A Synopsis of Anaesthesia (ed 10). Bristol, Wright, 1987. 
[19] Russel WJ, Morris RG., Frenin, DB. and Drew SE. Changes in plasma catacholamine concentrations during endotracheal intubation. Br.J. Anaesth. 1981; 53: 837-9.

[20] Cumin FM., Russel WJ., Frewin DB. and Johnson Jr. The effect of suxamethonium and d-tubocuvarine on the pressor and plasma catacholamine responses to tracheal intubation. Anaesth. Intensive Care 1983; 11: 103-6.

[21] Dr Anil Patel : LMA Flexible ${ }^{\mathrm{TM}}$ : A Practical Guide. Le Rocher, Mahe, Seychelles 2006.

TABLES

Table 1

Demographic and anaesthetic data

\begin{tabular}{|l|l|l|}
\hline & $\begin{array}{l}\text { Flexi L.M.A. }(\mathrm{n}=30) \\
\text { Group I (mean } \pm \text { SD) }\end{array}$ & $\begin{array}{l}\text { E.T.T. }(\mathrm{n}=30) \\
\text { Group II (mean } \pm \text { SD) }\end{array}$ \\
\hline Age (years) mean \pm SD & $6 \pm 2.3$ & $7.6 \pm 4.8$ \\
\hline $\begin{array}{l}\text { Sex ratio } \\
\text { Male: Female }\end{array}$ & $18: 12$ & $19: 11$ \\
\hline $\begin{array}{l}\text { Duration of anaesthesia } \\
\text { (minutes) } \pm \text { SD }\end{array}$ & $35 \pm 5.8$ & $33 \pm 4.8$ \\
\hline Cough & 1 & $6 *$ \\
\hline Strain & 1 & 2 \\
\hline Breath Holding & 1 & $6^{*}$ \\
\hline
\end{tabular}

* Significant value $(\mathrm{p}<0.05)$

Table 2

Hemodynamic and intraocular pressure changes in the two groups at different intervals

\begin{tabular}{|c|c|c|c|c|c|c|}
\hline \multirow[t]{2}{*}{ Parameters } & \multirow[t]{2}{*}{ Group } & \multirow{2}{*}{$\begin{array}{l}\text { Baseline } \\
\text { value }\end{array}$} & \multirow{2}{*}{$\begin{array}{l}\text { Before } \\
\text { insertion } \\
\left(\mathrm{T}_{0}\right)\end{array}$} & \multicolumn{3}{|c|}{ After insertion of Flexi LMA/ETT } \\
\hline & & & & 1 Min. $\left(\mathrm{T}_{0+1}\right)$ & $\begin{array}{l}2 \text { Min. } \\
\left(\mathrm{T}_{0+2}\right)\end{array}$ & $\begin{array}{l}3 \text { Min. } \\
\left(\mathrm{T}_{0+3}\right)\end{array}$ \\
\hline \multirow[t]{2}{*}{$\begin{array}{l}\text { HR( beats } \\
\left.\min ^{-1}\right)\end{array}$} & Flexi LMA & $82.88 \pm 6.96$ & $80.12 \pm 8.27$ & $\begin{array}{l}111.24^{*} \\
\pm 9.20\end{array}$ & $\begin{array}{l}104.60^{*} \\
\pm 14.71 \\
\end{array}$ & $\begin{array}{l}87.62 \\
\pm 9.20 \\
\end{array}$ \\
\hline & ETT & $82.68 \pm 9.21$ & $\begin{array}{l}81.68 \\
\pm 10.01 \\
\end{array}$ & $\begin{array}{l}121.16^{* / \#} \\
\pm 19.90\end{array}$ & $\begin{array}{l}104.62 * \\
\pm 13.85 \\
\end{array}$ & $\begin{array}{l}84.24 \\
\pm 13.40 \\
\end{array}$ \\
\hline \multirow[t]{2}{*}{$\begin{array}{l}\mathrm{MAP}(\mathrm{mm} \\
\text { of } \mathrm{Hg})\end{array}$} & Flexi LMA & $\begin{array}{r}60.20 \\
\pm 6.80 \\
\end{array}$ & $\begin{array}{r}62.80 \\
\pm 7.20 \\
\end{array}$ & $\begin{array}{l}86.10 * \\
\pm 10.60 \\
\end{array}$ & $\begin{array}{l}96.00 * \\
\pm 7.20 \\
\end{array}$ & $\begin{array}{l}66.10 \\
\pm 4.20 \\
\end{array}$ \\
\hline & ETT & $\begin{array}{l}62.80 \\
\pm 6.20 \\
\end{array}$ & $\begin{array}{l}62.10 \\
\pm 8.10 \\
\end{array}$ & $\begin{array}{l}108.10^{*} / \# \\
\pm 12.60\end{array}$ & $\begin{array}{l}124.02 * / \# \\
\pm 11.90\end{array}$ & $\begin{array}{r}64.20 \\
\pm 5.90 \\
\end{array}$ \\
\hline \multirow[t]{2}{*}{$\begin{array}{l}\text { IOP }(\mathrm{mm} \text { of } \\
\mathrm{Hg})\end{array}$} & Flexi LMA & $\begin{array}{l}16.11 \\
\pm 1.34 \\
\end{array}$ & $15.12 \pm 1.16$ & $15.20 \pm 2.10$ & $15.80 \pm 4.44$ & $\begin{array}{r}14.60 \\
\pm 3.62 \\
\end{array}$ \\
\hline & ETT & $15.82 \pm 1.50$ & $14.32 \pm 0.90$ & $\begin{array}{l}26.80 * / \# \\
\pm 5.25\end{array}$ & $\begin{array}{l}20.10 * / \# \\
\pm 4.85\end{array}$ & $\begin{array}{l}13.41 \\
\pm 2.73 \\
\end{array}$ \\
\hline
\end{tabular}

HR: heart rate, MAP = Mean arterial blood pressure, IOP = Intraocular pressure, Flexi LMA = FlexiLaryngeal mask airway, ETT: Endotracheal tube. $\mathrm{mm}=$ millimetre, $\mathrm{Hg}=$ Mercury Value are expressed as mean \pm SD. $*$ : Significant $(\mathrm{p}<0.05)$ vs Baseline in the same group.

\# Significant $(\mathrm{p}<0.05)$ Flexi LMA VS. ETT 


\section{GRAPHS}

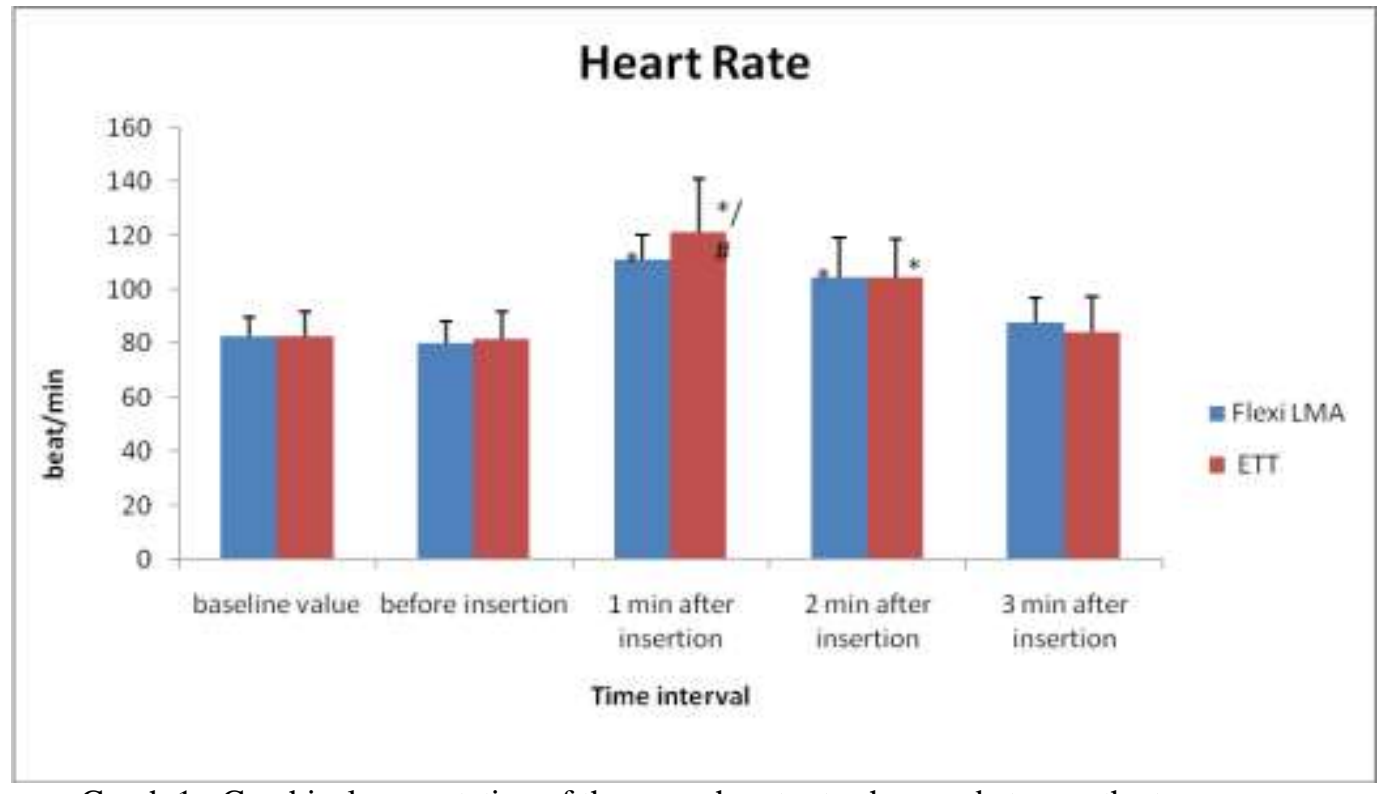

Graph 1: Graphical presentation of the mean heart rate changes between the two groups

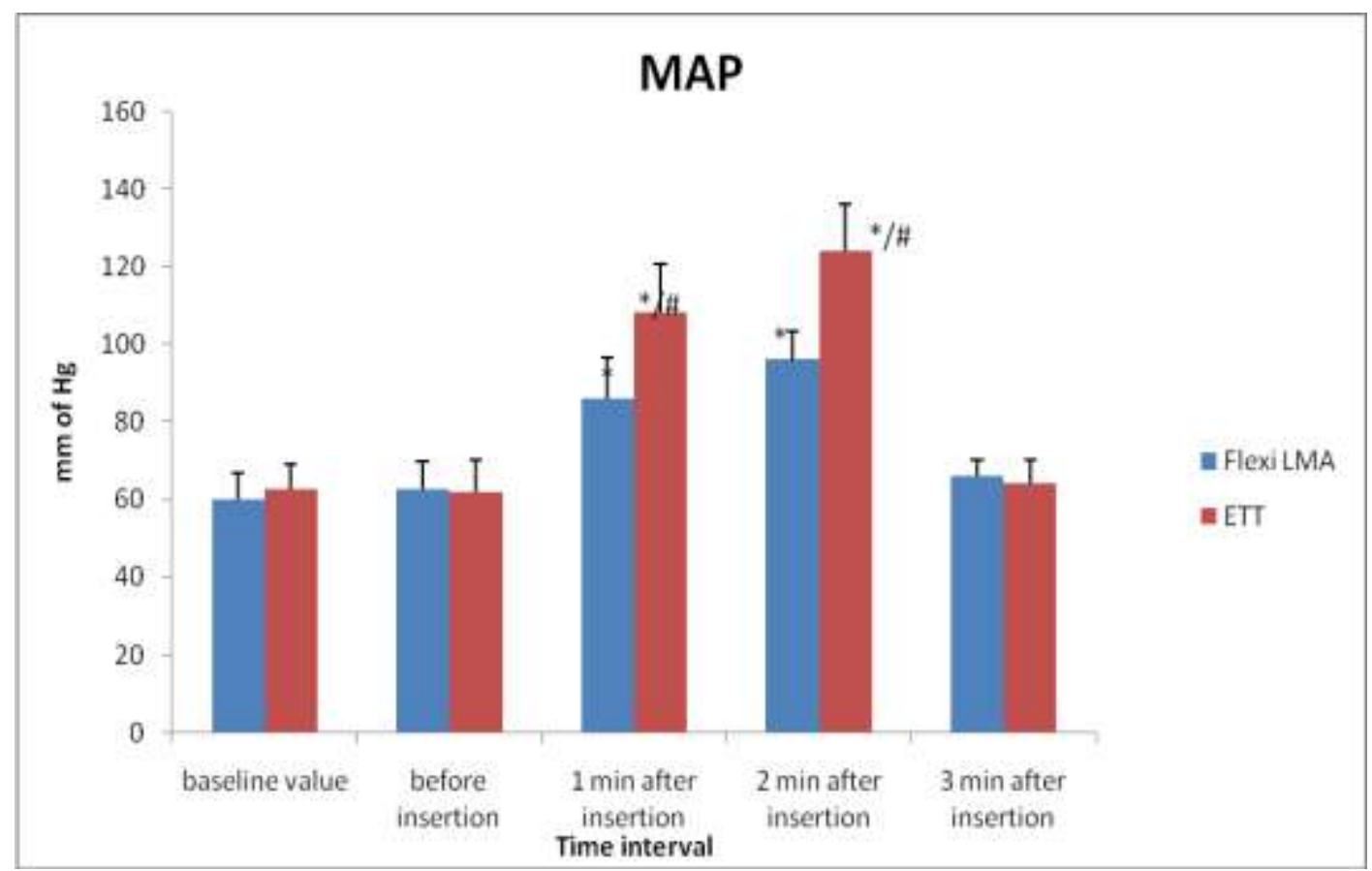

Graph 2: Graphical presentation of the mean arterial pressure changes between the two groups 


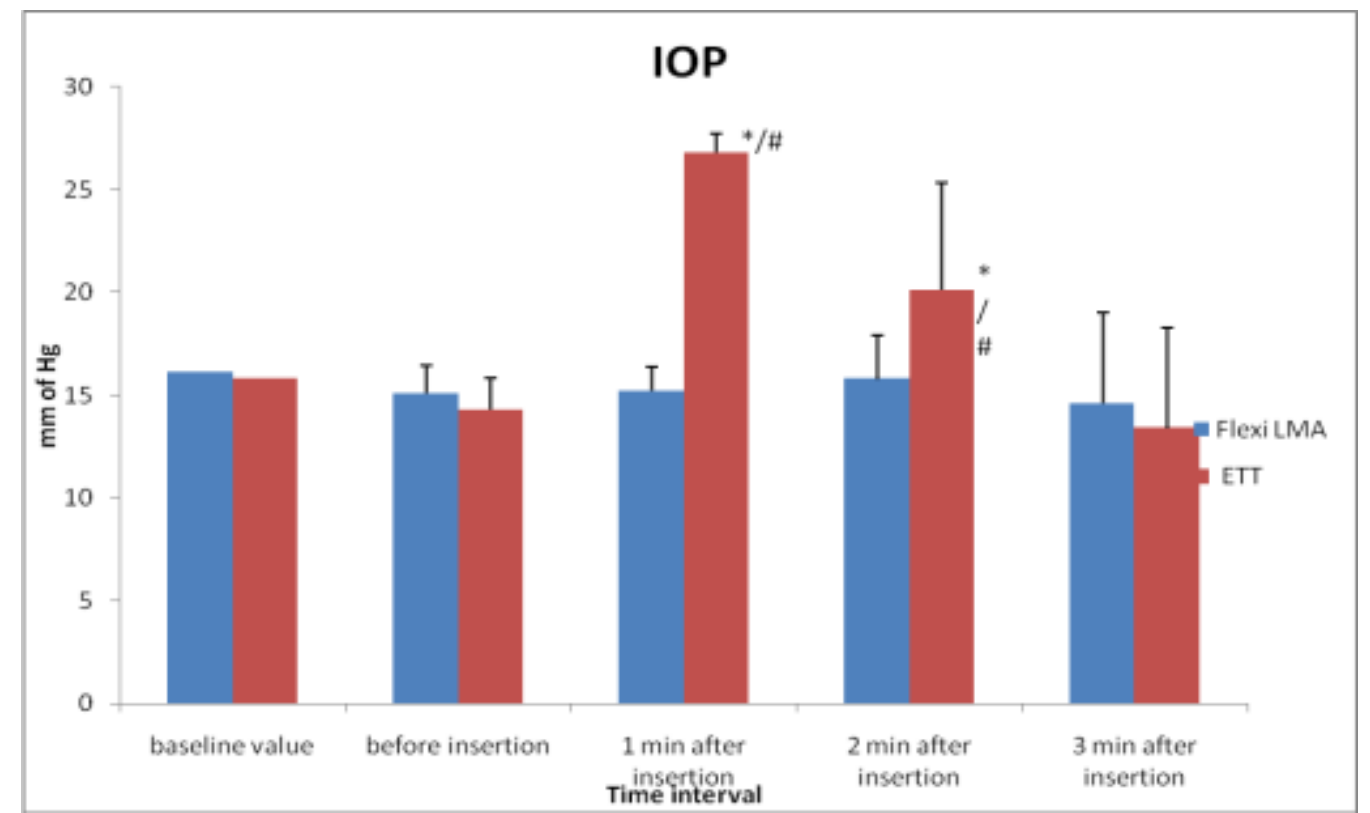

Graph 3: Graphical presentation of the mean Intraocular pressure changes between the two groups

HR: heart rate, MAP = mean arterial blood pressure, $\mathrm{IOP}=$ intraocular pressure, Flexi LMA $=$ Flexi Laryngeal mask airway, ETT: Endotracheal tube. $\mathrm{Mm}=$ millimetre, $\mathrm{Hg}=$ Mercury

Value is expressed as mean $\pm \mathrm{SD}$.

*: Significant $(\mathrm{p}<0.05)$ vs Baseline in the same group.

\#: Significant $(\mathrm{p}<0.05)$ Flexi LMA VS. ETT 